NBER WORKING PAPER SERIES

\title{
UNRAVELING REDUCES THE SCOPE OF AN ENTRY LEVEL LABOR MARKET: GASTROENTEROLOGY WITH AND WITHOUT A CENTRALIZED MATCH
}

\author{
Muriel Niederle \\ Alvin E. Roth \\ Working Paper 8616 \\ http://www.nber.org/papers/w8616 \\ NATIONAL BUREAU OF ECONOMIC RESEARCH \\ 1050 Massachusetts Avenue \\ Cambridge, MA 02138 \\ December 2001
}

Muriel Niederle: http://www.economics.harvard.edu/ niederle and Alvin E. Roth: http://www.economics.harvard.edu/ aroth/alroth.html. An earlier version of this paper was entitled "Input and Output in Gastroenterology." This work was partially supported by a grant from the National Science Foundation. We also thank David Brenner, M.D., Fred Gorelick, M.D., and Sean Sheehan, M.D. for agreeing to be interviewed about the demise of the GI match. Robert Beran, Elliott Peranson, and Cody Webb, M.D. helped orient us to the ongoing events in Gastroenterology. We thank David Cutler and Ernan Haruvy for helpful comments. The views expressed herein are those of the authors and not necessarily those of the National Bureau of Economic Research.

(C) 2001 by Muriel Niederle and Alvin E. Roth. All rights reserved. Short sections of text, not to exceed two paragraphs, may be quoted without explicit permission provided that full credit, including $\odot$ notice, is given to the source. 
Unraveling Reduces the Scope of an Entry Level Labor Market:

Gastroenterology With and Without a Centralized Match

Muriel Niederle and Alvin E. Roth

NBER Working Paper No. 8616

December 2001

JEL No. J41, J44, I00

\section{ABSTRACT}

From 1986 through 1997 the entry-level market for American gastroenterologists was organized by a centralized clearinghouse. Before, and since, it has been conducted via a decentralized market in which appointment dates have unraveled to well over a year before the start of employment. The career paths of gastroenterologists therefore offer a unique opportunity to examine the difference between the market when appointments are decentralized and early, versus when they are made later via a centralized clearinghouse. (Most centralized clearinghouses remain in use once established, and so there is no way to separate changes due to the clearinghouse from other changes that may have taken place over time.) We find that, both before and after the years in which the centralized clearinghouse was used, gastroenterologists are less mobile, and more likely to be employed at the same hospital in which they were internal medicine residents, than when the clearinghouse was in use. This suggests that the clearinghouse serves not only to coordinate the timing of appointments, but that it also increases the scope of the market, compared to decentralized markets with early appointments and exploding offers. This has implications for theories of market failure due to unraveling over time.

Muriel Niederle

Department of Economics

Harvard University

Cambridge, MA 02138
Alvin E. Roth

Department of Economics

Harvard University

Cambridge, MA 02138

and NBER

Al_Roth@harvard.edu 


\section{Introduction}

A common feature of many entry level labor markets is the "unraveling" of hiring decisions. At some point in the history of such markets, contracts come to be written quite far before actual employment starts. Two markets that are presently experiencing this kind of unraveling are the market for law clerks for Federal appellate judges (cf. Avery, Jolls, Posner and Roth 2001), in which offers are presently made almost two years in advance of employment, and the market for college admissions (cf. Avery, Fairbanks and Zeckhauser 2001), in which elite colleges admit a high percentage of their entering classes through "early decision" programs that require applicants to commit in advance to one college that they will accept its offer if they are admitted early. Roth and Xing (1994) describe several dozen such markets and submarkets.

Unraveling is typically a dynamic process, so that offers are made earlier and earlier from year to year. Furthermore, markets that experience unraveling tend to be markets in which applicants receive "exploding" or "short fuse" offers. That means an applicant has to accept or reject such an offer before she can gather all (or sometimes any) other offers she might receive from potential employers. In such a market, any firm that leaves its offers open for even a little time, and is eventually rejected, will often find that their alternative choices have already accepted offers elsewhere. Therefore, firms have an incentive to make exploding offers themselves, and the trend towards making exploding offers becomes self reinforcing.

Unraveling in a market can potentially impose two kinds of costs. There are the costs of potential mismatches, if information about the quality of applicants (and firms) only becomes available over time (so that there is important information that is 
unavailable when contracts are signed early than if they were signed later). ${ }^{1}$ "Exploding" offers may bring about another source of inefficiency. In a world of exploding offers, firms enjoy local market power (in time) and this may lead to mismatches (Roth and Xing 1997).

In many markets there have been vigorous and sustained efforts to halt the unraveling of appointment dates. However, efforts to simply impose uniform appointment dates have most often been unsuccessful. Some markets have successfully reorganized themselves around a centralized clearinghouse (Roth and Xing 1994). The best known example is the National Resident Matching Program (NRMP), through which 20,000 entry level medical positions are filled each year in the United States (cf. Roth, 1984, Roth and Peranson, 1999). Other examples include a variety of American medical and health care markets, entry level medical markets in Britain and Canada, and entry level markets for law graduates in some regions of Canada.

Because it is difficult to directly measure the qualities of a particular worker-firm match, let alone the efficiency of a matching of workers and firms at the market level, there has been no direct evidence bearing on the costs of unraveling, apart from experimental studies (Kagel and Roth 2000, Haruvy, Roth, and Ünver 2001). ${ }^{2}$ There is not even clear nonexperimental evidence that a centralized clearinghouse produces different matches than those observed in an unraveled decentralized market. The present

\footnotetext{
1 This includes information about future demand, as well as information about the professional qualifications of the applicants and their preferences.

${ }^{2}$ For example, Avery et al. (2001) discuss the difficulty of assessing the efficiency of different matchings of law clerks to federal judges, since there is no way to even begin to measure how this enters into the production of justice or social welfare. Similarly, we would not know how to begin to assess how different matchings of gastroenterology fellows and hospitals enter into the production of good health and social welfare.
} 
paper will present direct evidence of this latter sort, which also has a bearing on the costs of unraveling.

Recent theoretical work by Li and Rosen(1998), Li and Suen (2000), and Suen (2000) has shown how unraveling can occur in competitive markets. In these models, the market is competitive not only when it is organized through a centralized clearinghouse (or a decentralized market) at a uniform, efficient time, but also when the market unravels, and clears inefficiently early. In these models, the costs of unraveling arise as costs of mismatching due to the fact that there remains uncertainty over applicants' (or firms') quality when contracts are written far in advance. In this case early contracts can provide insurance for risk averse market participants. ${ }^{3}$ In general, parties that contract early benefit from unraveling, while others might be worse off. Unraveling is ex ante efficient, but ex post inefficient, due to the mismatches from forming early contracts. In such models a centralized clearinghouse may be introduced for two reasons. One possibility is that firms simply form a cartel. By having applicants match to firms via a centralized clearinghouse, firms may not have to compete for applicants by paying them competitive wages (see also Kamecke 1998). Another possibility is that those parties that suffer early contracting are able to enforce a uniform late contract date, in which mandatory participation in a centralized clearinghouse serves as an enforcement device.

\footnotetext{
${ }^{3}$ Specifically Li and Rosen model uncertainty over applicants' qualifications and uncertainty over aggregate supply (i.e. whether the applicants or the firms will be on the long side of the market). Early contracting can then provide partial insurance for both the ex ante promising (but maybe still ex post unqualified) applicant, and the firm. Li and Suen show that aggregate uncertainty is not necessary for such results. They assume uncertainty about applicants' and firms' quality, and complementarities between those qualities. When workers and firms are symmetric, early contracting provides risk sharing regarding the uncertain future productivity and happens among ex ante highly productive firms and applicants ("topclearing contracting"). When applicants are risk averse but firms are risk neutral, there can be equilibria in which promising workers (who care about risk-sharing), but not promising firms (who care more about sorting efficiency) contract early.
} 
Roth and Xing (1994) identify an additional potential cost of unraveling, namely that as markets unravel, they become thinner and less competitive, as different firms make offers at different times. By making exploding offers, firms limit the options of applicants to consider alternative offers and hence can exercise local market power. (See for example the description of the contemporary market for law clerks in Avery et al. 2001.) According to this hypothesis, this loss of liquidity in the market reduces the scope of the market, and forces firms to rely more on local applicants. For example, in the United Kingdom, when the market for entry level medical positions unraveled to over a year before students graduated from medical school, positions at teaching hospitals seemed often to be filled with students from the associated medical school (Roth 1990, 1991). In Japan, early recruiting is often accomplished through informal "old boys" networks, in which graduates from a given university are recruited by former students of that university (Roth and Xing 1994, Rebick, 2000). If unraveling causes the market to become thin in this way, a centralized clearinghouse can then help not only to stop the unraveling and control the timing of the market, it may additionally increase the scope of the market, and reduce the need for market participants to rely on informal networks.

To summarize, both competitive and noncompetitive models of unraveling imply ex post inefficiency of the market. However, efficiency of a match is difficult to observe in the field (as opposed to in experiments). The main difference between the "purely competitive" and noncompetitive hypotheses is whether a centralized clearinghouse solely regulates the timing at which the market takes place. In the existing competitive models, the market is competitive at whatever time it operates. An alternative hypothesis, suggested by descriptive accounts of some deeply unraveled markets with exploding 
offers, etc. is that they limit the scope of the market-i.e. the range of offers and candidates that can be considered. In that case the centralized clearinghouse may also reduce local market power, lead to more liquidity and increase the scope of the market.

In the present paper, we will look for evidence that a centralized clearinghouse affects the scope of the market, by examining the career-paths of market participants, with and without a centralized match. The idea is to see if, without a centralized match, employers are able to cast as wide a net as when there is a centralized match. The alternate hypothesis is that a centralized match supports a national market, while an unraveled market is likely to break down into many local markets.

There is a considerable difficulty in finding data that address this question. For example, we cannot simply look at the career paths of American doctors before and after the introduction of the first centralized match in 1951. Many other changes in the medical profession and the general economy have influenced the mobility of physicians since that time, so even if we find that physicians are less likely to take their first job at a local hospital since the introduction of the match, this could hardly be counted as evidence that this was due to introduction of the centralized clearinghouse.

Ideally we would like to consider a profession in which we have observations both before a centralized match was instituted and after it was removed, to be able to attribute different career paths to changes in the matching mechanism and not to changes due to changes over time in the way a profession is organized.

The internal medicine subspecialty of Gastroenterology provides us with such a unique opportunity. As will be described below, Gastroenterology had a centralized match from 1986 to 1997, and an unraveled, decentralized market both before and since. 
Thus the mobility of entry-level gastroenterologists can be tracked over time, and the effects of both the introduction of a centralized clearinghouse, and its demise, can be observed.

Our results show a significant increase in mobility of Gastroenterology fellows during the match, both compared to before the match was in place and after the demise of the match. This provides the first evidence that the use of a centralized clearinghouse leads to different matchings, and that unraveling may reduce the scope of the market.

\section{Gastroenterology}

Gastroenterology is a subspecialty of internal medicine. A typical GI fellow (so called because of the older name of Gastro-Intestinal disease) will therefore have first gone 4 years to college, then 4 years to medical school, then been employed for 3 years as a resident in internal medicine (qualifying to be a Board certified specialist in internal medicine), and finally started a GI fellowship, at the end of which he will be eligible to be a Board certified subspecialist. GI fellowship positions were allocated via a decentralized market until 1985. Like many medical markets and submarkets (Roth and Xing, 1994) it suffered from the unraveling of appointment dates, and attempted a number of solutions prior to adopting a centralized match. ${ }^{4}$ In 1986 the Medical Specialties Matching Program (MSMP) was initiated by the NRMP at the request of the

\footnotetext{
${ }^{4}$ For example, Dr. David Brenner, then Chair of the AGA's Manpower and Training Committee, in an interview in Spring 1999, in the Trainee and Young GI News of the American Gastroeterology association: "Before the match, an approach of setting guidelines for interviewing candidates and negotiating positions was tried, and it was unsuccessful. Some applicants and programs received calls asking them for decisions three months before the deadline. Since it was only a recommended policy, directors say, it was terribly abused, which is why the training directors developed the match. Many felt that there was a chaotic atmosphere."
} 
Association of Professors of Medicine, the Association of Program Directors in Internal Medicine and the Council of Sub-Specialty Societies of the American College of Physicians. From 1989 the match was conducted for Gastroenterology, Cardiovascular Disease, Pulmonary Disease and since 1994 also for Infectious Disease (all internal medicine subspecialties.) The objective was to establish a uniform appointment date for internal medicine fellowship positions which would permit applicants to complete at least two years of their residency before making a decision as to which sub-specialty to pursue. The fellowship clearinghouse was conducted a year in advance, i.e. after two years of internal medicine residency, and one year before employment would begin (MSMP 1999).

In such a clearinghouse, applicants and hospitals submit rank order lists over positions and applicants, respectively. Then the deferred acceptance algorithm, with hospitals proposing is used. This produces stable matchings (cf. Gale and Shaply, 1962, Roth and Sotomayor, 1990). However, in the years 1997 to 1999 the centralized match suffered from defections, broke down, and was abandoned. The demise of the match can be clearly seen in the number of positions that were filled through the match each year: While in 1996 around 300 positions participated in the match, by 1999 there were only 14 and in 2000 there was no match for Gatroenterologists.

The demise of the match seems to have been set in motion in 1993-1994, when, in the midst of general discussions of health care reform, the subspecialty of Gastroenterology subjected itself to a manpower analysis. The resulting study was published in 1996 in the Journal of the American Medical Association (Meyer et al 1996). Its main conclusions are that the US health care system and gastroenterologists 
would benefit from a reduction in gastroenterology Fellowship programs. ${ }^{5}$ The Gastroenterology Leadership Council endorsed a goal of $25 \%$ to $50 \%$ reduction in the number of GI fellows over 5 years. Furthermore, an additional year of training was mandated: starting in the summer of 1996, three years of training were required to be board eligible, instead of two.

That is, starting in 1996 the demand for gastroenerology fellows was sharply reduced, by administrative decision of the specialty board, and the cost of becoming a gastroenterologist was raised by a year (although some three-year fellowship programs had already existed before 1996).

However, this triggered an even sharper reduction in the number of residents who applied for GI fellowship positions and seems to have been the starting point of the demise of the match. In 1996, for the first time, and despite the reduction in the number of positions offered, there were fewer applicants for GI fellowship positions than there were positions offered in the match. This seems to have triggered a scramble among fellowship programs that led to the demise of the match. Dr. David Brenner, then Chair of the AGA's Manpower and Training Committee, in an interview in Spring 1999, AGA: Trainee and Young GI News, described that demise in part as follows:

"Last year, several applicants complained because many training programs did not use the match. Many applicants were un-aware of this change and they felt that they had missed opportunities. Training-program directors who used the match felt that they had lost applicants to programs that had secured fellows before the match. Many applicants and a large percentage of the fellowship

\footnotetext{
5 The cartel-like aspects of medical specialty boards in their role of deciding how many entry level positions to accredit each year is beyond the scope of the present paper.
} 
programs stopped using the match, which made choices more difficult for the remaining applicants and programs and created a vicious circle. Many training directors were very disappointed a few years ago when they didn't fill their slots because the applicants they thought were interested accepted positions before the match."

The following table shows for each year in which the match took place (one year before the fellowship starts), the results of the match. It gives the number of positions and the number of applicants who participated.

\begin{tabular}{|c|c|c|c|c|c|c|c|c|}
\hline Yr & $\begin{array}{c}\text { Positions } \\
\text { advertised }\end{array}$ & $\begin{array}{c}\text { Posts } \\
\text { with- } \\
\text { drawn }\end{array}$ & $\begin{array}{c}\text { \% with- } \\
\text { drawn }\end{array}$ & $\begin{array}{c}\text { Posts } \\
\text { in } \\
\text { Match }\end{array}$ & $\begin{array}{c}\% \\
\text { matched }\end{array}$ & $\begin{array}{c}\# \\
\text { progr } \\
\text { ams }\end{array}$ & $\begin{array}{c}\# \\
\text { Applica } \\
\text { nts }\end{array}$ & $\begin{array}{c}\text { \# Appl. / } \\
\text { Post. in } \\
\text { Match }\end{array}$ \\
\hline '92 & & & & 377 & 96.6 & 160 & 658 & 1.75 \\
\hline '93 & 374 & -25 & -0.067 & 399 & 94 & 173 & 642 & 1.6 \\
\hline '95 & 351 & 14 & 0.04 & 337 & 88.7 & 171 & 433 & 1.3 \\
\hline$' 96$ & 313 & 15 & 0.048 & 298 & $\mathbf{7 4 . 8}$ & 164 & 277 & $\mathbf{0 . 9}$ \\
\hline '97 & $\mathbf{2 5 4}$ & $\mathbf{4 1}$ & $\mathbf{0 . 1 6 1}$ & $\mathbf{2 1 3}$ & $\mathbf{8 5}$ & $\mathbf{1 2 8}$ & $\mathbf{2 4 0}$ & $\mathbf{1 . 1}$ \\
\hline '98 & 178 & 79 & 0.443 & 99 & $\mathbf{7 7 . 8}$ & 60 & 148 & 1.5 \\
\hline$' 99$ & 35 & 21 & 0.6 & 14 & & 11 & & \\
\hline
\end{tabular}

Table 1: For each year, Positions advertised is the number of positions whose availability in the match was announced in late March. Until late May, the programs may add or withdraw positions (Posts withdrawn), which leaves the final number of positions in the match (Posts in Match.) \# Applicants is the total number of applicants that listed at least one GE program in their rank order list. 
As noted above, 1996 was the first year that the total number of applicants for Gastroenterology fellowship positions was lower than the total number of positions offered, with a ratio of 0.9 . Only $75 \%$ of the positions that participated in the MSMP got matched that year, a considerable reduction from previous years. 1997 was the first year in which a large percentage of positions withdrew from the match, presumably in part because they noticed that the market was starting to unravel, and moved early to assure themselves of filling their positions with qualified applicants. We will view 1997 as the first year in which the market was no longer effectively organized via the centralized match. (That is, GI fellows who began employment in 1998 and hence finish in 2001 will have obtained their job after the match had started to break down).

Once the match broke down, and the commitment to uniform late appointment dates vanished, the market for Gastroenterology fellows once again experienced unraveling and exploding offers. The following quotes, all from the leading field journal Gastroenterology in 1999, make this clear. ${ }^{6}$

In a Letter GI Fellows Bauer, Fackler, Kongara, Matteoni, Shen and Vaezi (1999) comment on the effects of the demise of the match.

"Of recent concern is the deterioration of the match process for candidates applying for fellowship positions over the past two years. Our junior colleagues are concerned that they may not be able to wait safely to interview with the institution of their choice while a position is offered elsewhere early in the

\footnotetext{
${ }^{6}$ The Organization that organizes the Match, NRMP, also changed its policy, presumably to forestall similar breakdowns in other fields. Effective July 1, 2001, NRMP requires the sponsoring organization to sign an "NRMP Program Directors Annual Participation Agreement" annually committing active participation of at least $75 \%$ of the eligible programs and a minimum of $75 \%$ of all available positions in the specialty for a given year. Subsequent failure to register $75 \%$ of programs and/or positions in a given year jeopardizes the NRMP's managing future matches.
} 
decision process. The absence of the match benefits the programs a great deal more than their applicants."

Gorelick (1999) in a Comment from the Editors, speculates about the reasons of the demise of the match, and confirms unraveling.

"The reasons for the decline of the match include fewer applicants to the Gastroenterology Match, and the inopportune timing of interviews and the Match. This year the reduced applicant pool led to earlier interviews and the virtual abandonment of the Match.

This downward trend in applicants to GI programs may have reversed this year and may remain stable for the foreseeable future. However, the movement toward earlier interview dates is likely to continue. Indeed some programs will be conducting their interviews almost 2 years before the trainee's start date". ${ }^{7}$

The market also experiences some of the other "typical" costs associated with unraveling, apart from mismatching. The first is that when the time comes to begin employment, some applicants fail to fulfill their obligation, made two years in advance, to join the program whose offer they have accepted. Second, internal medicine residents may not want to consider Gastroenterology, because they are not willing to commit to a

\footnotetext{
${ }^{7}$ Furthermore, applicants are usually in the midst of difficult and sleep-depriving rotations characteristic of their second year residency. In an interview, one fellowship director indicated that an additional disadvantage of interviewing so far in advance is that applicants tend to fall asleep during the interview.
} 
subspecialty this early. Interviews now take place before they have the opportunity to explore other subspecialties (Gorelick 1999). ${ }^{8}$

\section{The data}

We purchased from the American Medical Association (via Medical Marketing Service, Inc.) a dataset that contains all living physicians who either have completed, or are currently completing a Gastroenterology fellowship, are board certified gastroenterologists or claim Gastroenterology as a specialty. For each physician we obtained information on the career path, i.e. the medical school they attended, and the residencies and fellowships they completed. The data specifically contain the years in which each physician graduated from medical school and finished each residency, the specialty of the residency (e.g. Internal Medicine, Gastroenterology), the name of the institution where the residency was done, and the city and the state of the institution.

The file contains 15,187 entries. Of those, 10881 have been or are enrolled in a Gastroenterology (GI) fellowship. ${ }^{9}$ Of these 10881 with a GI fellowship, 10553 also completed a residency (in the US) before their GI fellowship. The largest number of active gastroenterologists completed their fellowships after 1977, from which point on there were at least 260 physicians completing a GI fellowship. Only 177 physicians completed a GI fellowship in 1976 and fewer than 100 per year for all the years before that. Furthermore, our data are incomplete for the most recent years: Our last observation will be 2003 (date of completion of fellowship), for which we have 156 fellows (whereas

\footnotetext{
${ }^{8}$ Indeed, a survey of internal medicine residents indicates that $2 / 3$ of residents feel that they are not ready to make a decision to commit to a subspecialty fellowship in their second year and would prefer to delay that decision until their third year (AGA 2001).
} 
we have only 5 fellows in 2004), ${ }^{10}$ see Figure 1 . We will compare the mobility of physicians between the last residency before their GI residency and their first GI residency (a few have two). In our results the year of the GI residency always refers to the year in which the GI fellowship is to be completed. ${ }^{11}$

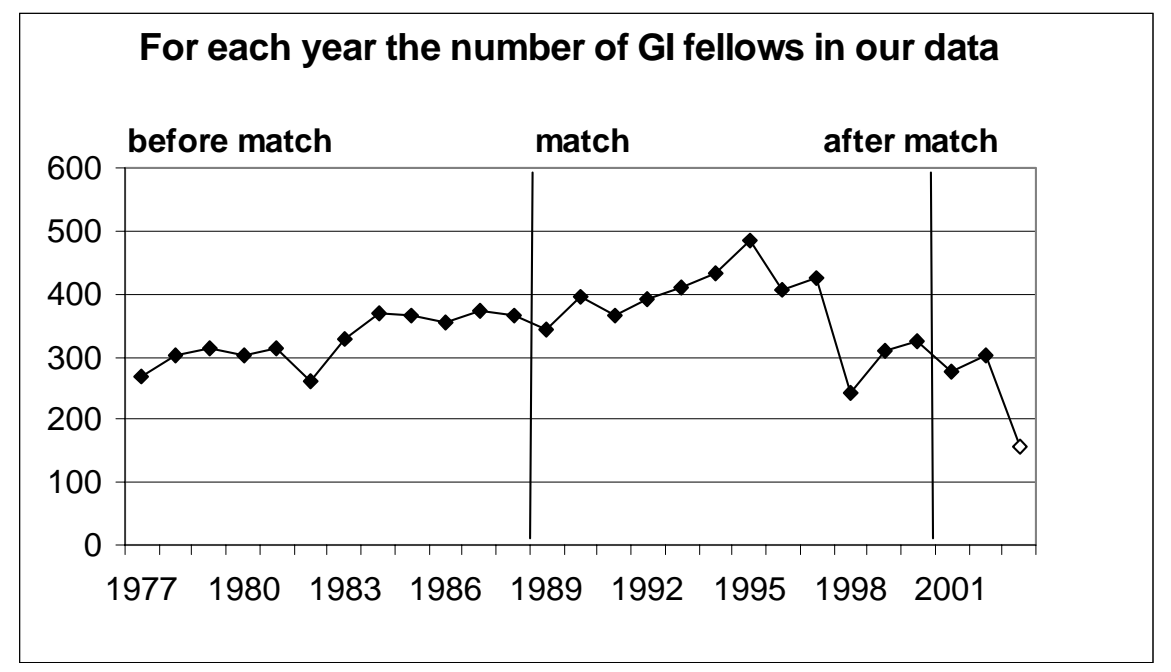

Figure 1: For each year, the number of presently active physicians who finished (or will finish) their GI fellowship in that year. The match was instituted in 1986, for positions starting in 1987, lasting two years hence finishing in 1989. Analogously the match broke down in 1997, with fellowships now lasting three years, so 2000 marks the demise of the match. The year 2003 is represented by a hollow point, since our data set may not contain all such fellows.

\footnotetext{
${ }^{9}$ Of the residual 4306 people, 3177 are actually board certified, the others only claim Gastroenterology as a specialty.

${ }^{10}$ The physicians who finish their GI fellowship in 2003 (and hence mostly started in 2000) are as yet incompletely reported in our data set. The fellowship positions are reported by the hospitals, and entered by the American Medical Association, a process which takes some time.

${ }^{11}$ Note that the number of fellows does not match the number of positions offered through the match. This reflects that even when the match was in place, some positions were filled outside the match. Also, the length of positions is not necessarily the minimum number of required years. For example, $45 \%$ of positions were 3 year positions in 1993, when the requirement to be board eligible was still only 2 years (Meyer et al 1996).
} 
The vertical lines correspond to the introduction, and the demise of the match, respectively. The first match was in 1986, for positions that start in 1987 and last (in general) 2 years, i.e. fellows who finish in 1989. Analogously, as described above, we consider the year of 1997 as the first year in which a large number of positions were filled outside the match, these are fellows who start their residency in 1998, and, the requirement now being 3 years, finish in 2001 .

This leaves us with 9180 fellows who did GI fellowships in 433 different hospital codes coming from 680 places. $^{12}$

\section{Mobility of Gastroenterologists with and without a Match}

Our main objective in this paper is to investigate whether the use of a centralized clearinghouse to match GI fellows to hospitals has an effect on the resulting matching of applicants to hospitals. Our data allow us to measure changes in the scope of the market. We compare the mobility of GI fellows when there is a match to the mobility without a match. A GI fellow moves whenever the GI fellowship is at a different hospital than the residency before the GI fellowship.

In Figure 2, the mobility over hospitals (Hosp) is the percentage of GI fellows that change hospital after finishing their (mostly) internal medicine residency and starting the gastroenterology fellowship. The mobility over City and State measures the percentage of fellows who move to a different city and state, respectively.

\footnotetext{
12 There is a potential bias in the data due to the fact that hospitals that change name due to mergers, etc. are coded as different hospitals. We address this problem below by also analyzing the data after removing data involving the first three years that any GI fellowship (to remove spurious incidence of "mobility" between a hospital and the same hospital under a different name), and find that this does not change any of our results.
} 


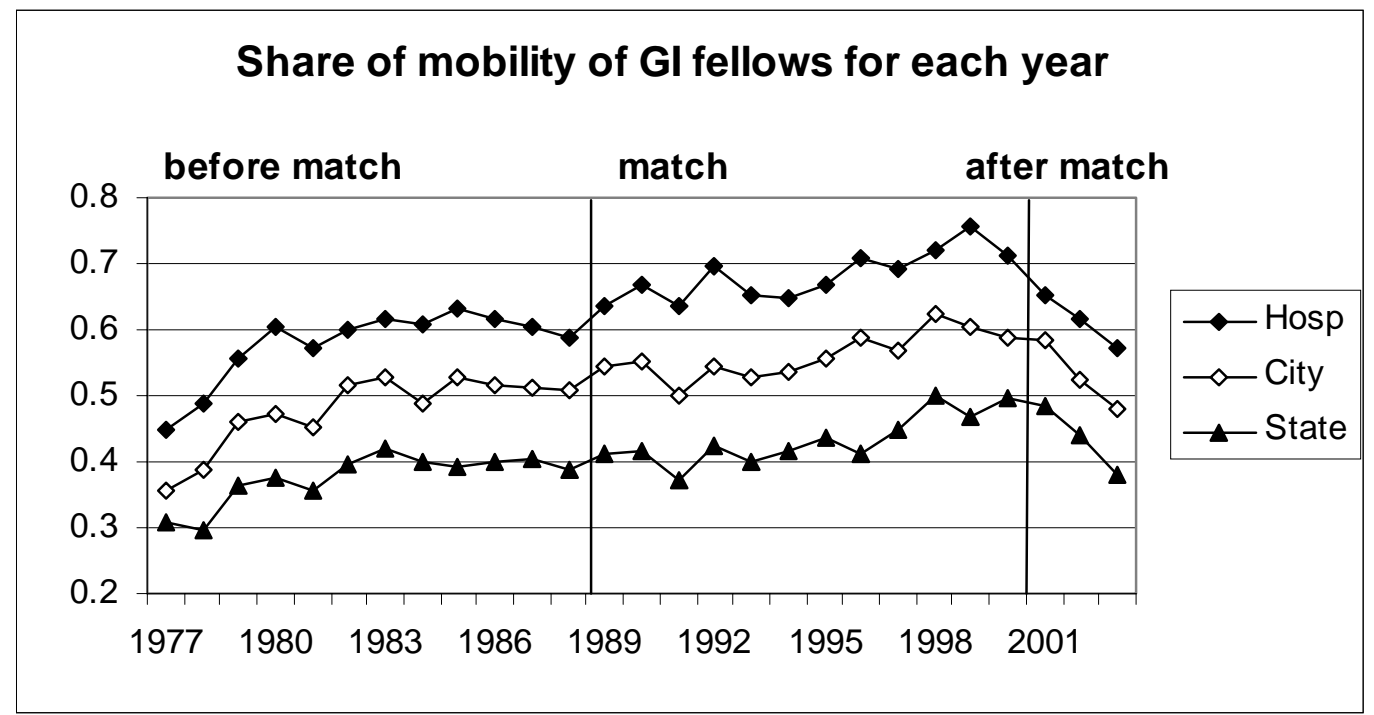

Figure 2: The vertical lines indicate again the beginning and the end of the use of the centralized match, measured in year of Fellowship completion.

The following Table 2 indicates average mobility (averages across years), where we also divide the 12 years of the match in the first and the last six years (M1 and M2 respectively).

\begin{tabular}{|c|c|c|c|c|c|c|}
\hline Mobility & $\mathbf{7 7 - 8 8}$ & $\mathbf{8 0 - 8 8}$ (Pre) & $\mathbf{8 9 - 9 4}$ (M1) & $\mathbf{9 5 - 0 0 ~ ( M 2 ) ~}$ & $\mathbf{8 9 - 0 0 ~ ( M ) ~}$ & 01-03 (Post) \\
\hline Hosp & 0.578 & 0.605 & 0.656 & 0.710 & 0.683 & 0.614 \\
\hline City & 0.477 & 0.502 & 0.534 & 0.588 & 0.561 & 0.530 \\
\hline State & 0.375 & 0.392 & 0.407 & 0.460 & 0.433 & 0.433 \\
\hline
\end{tabular}

Table 2

Table 3 provides the differences across mobility with $p$-values, where we use a two sided Mann Whitney $U$ test, with the proportion of mobility in each year as our data points. 


\begin{tabular}{|c|c|c|c|c|c|c|}
\hline Difference & M - Pre & M1 - Pre & M2 - M1 & Post - M2 & Post - M & Post - Pre \\
\hline Hospital & 0.079 & 0.052 & 0.053 & -0.096 & -0.069 & 0.009 \\
& $(.0001)$ & $(.0015)$ & $(.0163)$ & $(.0201)$ & $(.0433)$ & $(0.5175)$ \\
\hline City & 0.059 & 0.032 & 0.054 & -0.058 & -0.031 & 0.028 \\
& $(.0008)$ & $(.0184)$ & $(.0039)$ & $(.0707)$ & $(.1939)$ & $(0.4054)$ \\
\hline State & 0.041 & 0.014 & 0.053 & -0.026 & 0 & 0.041 \\
& $(.0045)$ & $(.0990)$ & $(.0250)$ & $(.4386)$ & $(.8852)$ & $(0.2294)$ \\
& & & & & & \\
\hline
\end{tabular}

Table 3

The introduction of a centralized clearinghouse significantly increases mobility across hospitals, across cities and across states. That this increase is gradual as measured over the first and second six-year periods of the match conforms with experimental results (Kagel and Roth 2000), in which the introduction of a centralized match only gradually becomes fully used by participants. Mobility sharply declines after the demise of the match lends strong support to the hypothesis that the increase in mobility during match years in indeed due to the match, and not to a general change in mobility of physicians over time. This suggests that the centralized clearinghouse has an important effect on the match that is produced, not only its timing. This in turn supports the hypothesis that the unraveled, early market is narrower in scope than the later market conducted via the centralized match.

But there is another possible explanation for the increase in mobility during the use of a centralized clearinghouse. It may be that when a centralized system is in place, different internal medicine physicians, specifically physicians who have always been 
more mobile, choose to become gastroenterologists. To control for this possibility, we now compute for each GI fellow a measure of mobility that corresponds to a change in city or state after finishing medical school and moving to the residency completed just before entering their GI fellowship. For this purpose we discard all foreign graduate students, reducing the sample to 6789 physicians. ${ }^{13}$ (This measure will also allow us to better interpret the absolute levels of mobility we find in moving from residency to fellowship.)

The following graphs compare mobility from medical school to residency and from residency to GI fellowship. To keep track of the same individuals, they are always tabulated in the year of completion of the GI fellowship. Since the students are not employed by the medical schools, they always move at the institutional level, so we compare mobility only over city and state.

\footnotetext{
${ }^{13}$ These are all physicians who studied in the US, Canada or Puerto Rico, whose fellowship programs are represented in our data set.
} 


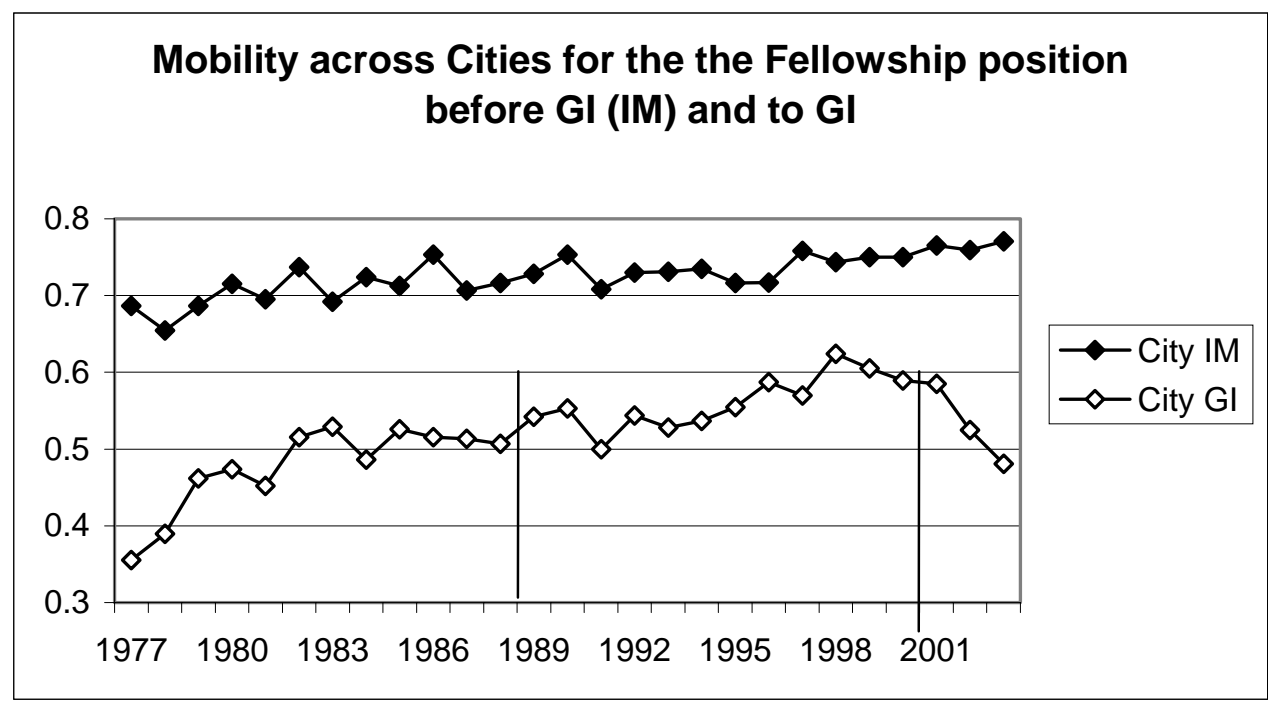

Figure 3a: Mobility of fellows who finish their GI fellowship in any given year across cities. The "City GI" line represents mobility across cities from residency to GI fellowship (as in Figure 2), while "City IM" reflects, for the same fellows, mobility between medical school and the last fellowship before GI (mostly IM: internal medicine). The vertical lines represent the beginning and the end of the match.

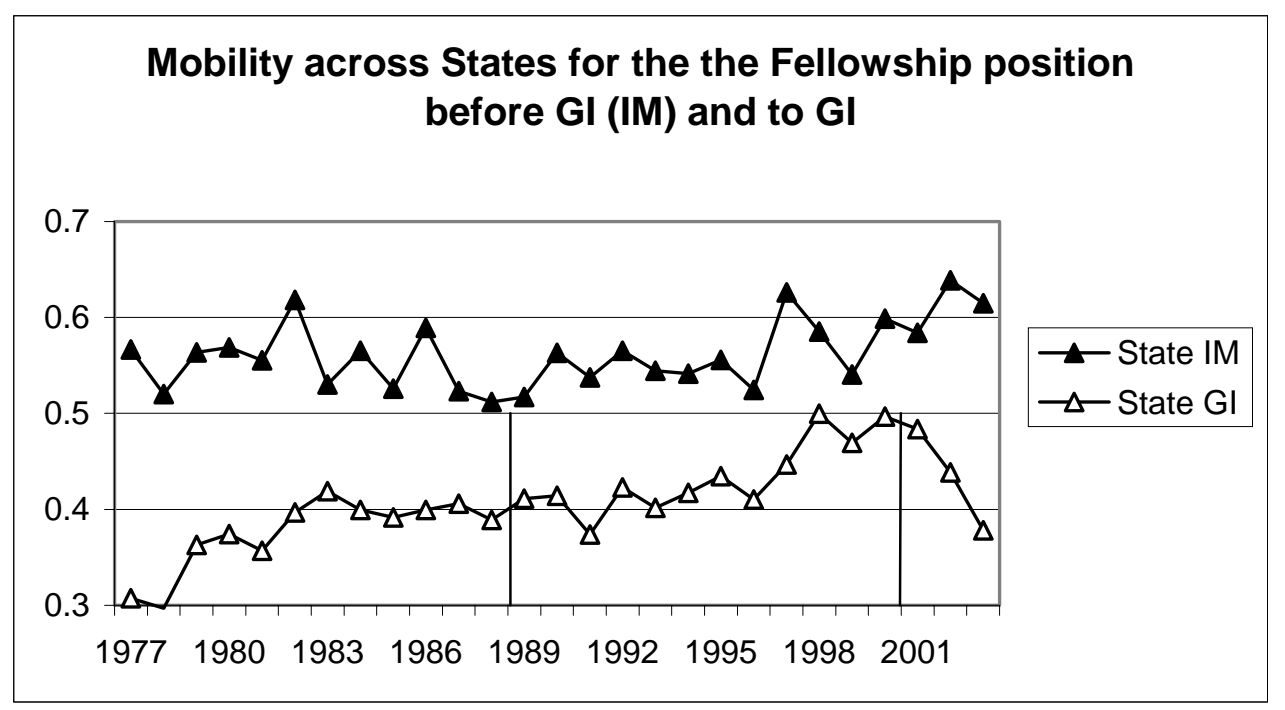

Figure 3b: Same as Figure 3a, for mobility across states. 
First we note that, unsurprisingly, physicians become less mobile as they advance in their careers. Second, there is no evidence that the change in mobility of GI fellows during the centralized match is driven by an increase in mobile physicians choosing to become Gastroenterologists. On the contrary, the mobility of fellows between medical school and their fellowship before GI is, slightly, increasing over time. That is, even though there is a striking decline in mobility of GI fellows before and after the match, when the same individuals were younger, and entering their IM residencies, they showed no difference in mobility, at either the city or state level.

This also makes clear why studying Gastroenterologists, for whom we have data not only before the institution of a centralized match, but also after its demise, allows us to separate changes in mobility due to changes over time from changes in mobility due to the market mechanism in place.

Next we control for several potential biases that might appear in our data set, to make sure that our results are not artifacts of the way the data were collected or coded.

First, note that for the year 2003 we have only 156 fellows as opposed to around 300 for the years 2001 and 2002. GI fellows who finish in 2003 start in 2000, so we assume that the AMA did not receive notice from all hospitals yet. To control for the possibility of a biased subset of universities that submit information about fellows on time, we consider the mobility of GI fellows in the years 1980 to 2002 for only the universities that report fellows in $2003 .{ }^{14}$ For the years 2001 and 2002, mobility of fellows at those hospitals is higher at every level (hospital, city and state), suggesting a possible bias of the data point of 2003 against our hypothesis. Furthermore, analyzing the

\footnotetext{
${ }^{14}$ Since a bias might only occur for the year 2003, we are mainly concerned in replicating the effects of the demise of the match, as opposed to the introduction of the match.
} 
effects of the failure of the match on mobility for only hospitals that report fellows in 2003 , reveals patterns that closely follow the ones when we consider all hospitals. ${ }^{15}$

Another possible bias stems from the fact that due to the consolidation of hospitals in the 90's, some hospitals in our data set change their name and also receive a new hospital code. Therefore it is possible that a physician who absolves her IM residency and her GI fellowship at the same hospital, might still be coded as moving hospitals, solely because her hospital changed its name. This bias would be an alternative explanation for our findings of increased mobility during the match at the hospital level, though of course not at the level of the city or the state.

To control for this source of bias we eliminate for each hospital the first three years of observation. The proportion of GI fellows who finish their GI fellowship 3 years after their last residency is always at least $70 \%$. The results are comparable to our previous table. $^{16}$

Furthermore, we divide our sample into big and small hospitals (being a proxy for more or less desirable hospitals, since tertiary hospitals tend to be both large and to

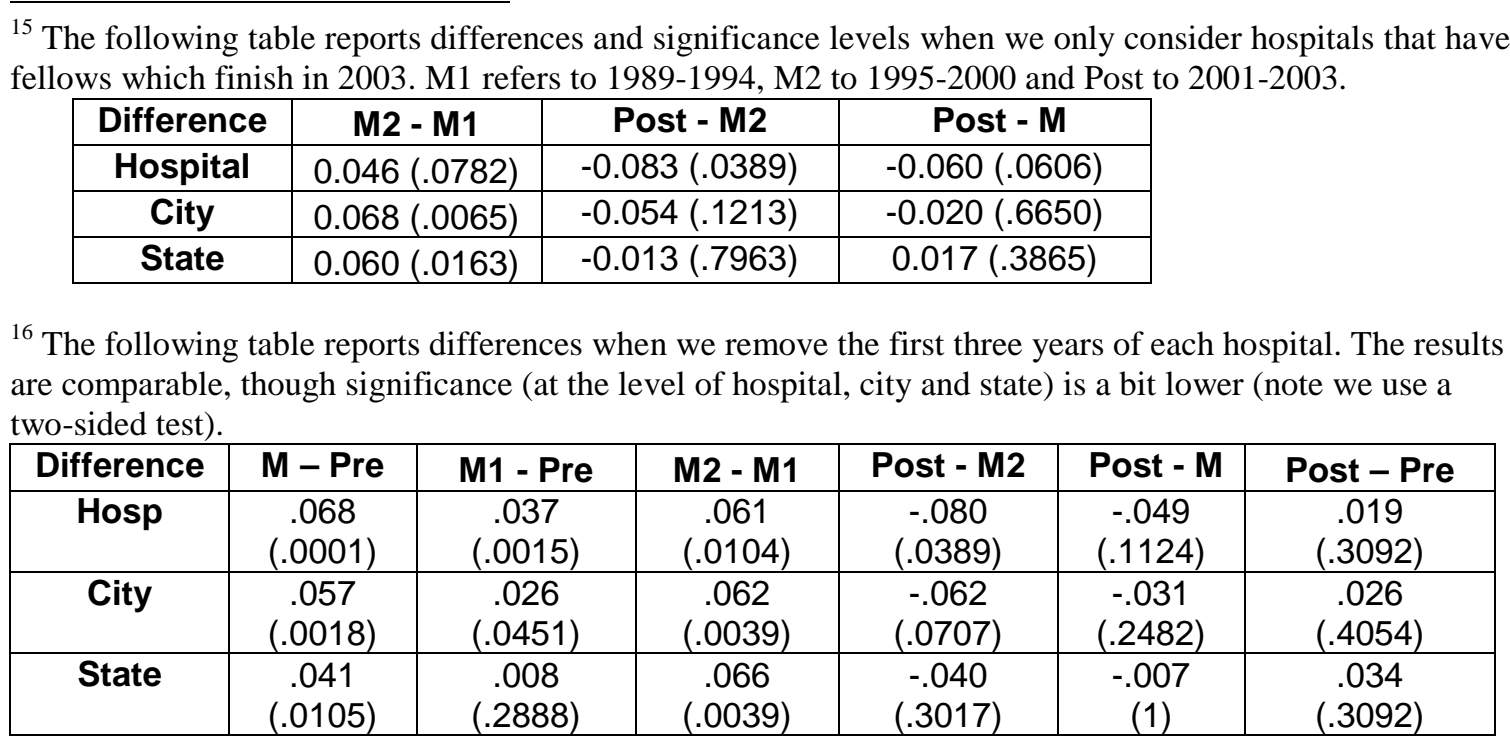


deal with a wider variety of diseases). We find that larger hospitals hire significantly fewer local fellows than small hospitals (at the hospital, city and state level). Furthermore the effects of the match are larger and more significant for large universities than for small universities. ${ }^{17}$

To test whether the match has a differential impact for different fellows we divided our sample between men and women, who first were about 5\% to up to $15 \%$ of the GI fellows. We find that women are less mobile than men, though the match has no effect on the differential of mobility.

\section{Conclusions}

This paper provides the first nonexperimental evidence that the use of a centralized match has an effect on the kinds of matchings produced by the market. When gastroenterology fellowship positions were offered through a centralized clearinghouse, the market became significantly more national than it was before the match, or since its demise. The mobility of GI fellows, as measured by whether their GI fellowship is in the same hospital, city or state as their former residency, significantly increased with the use of a centralized match.

Our results have implications for models of matching and the effects of unraveling. When markets unravel to very early appointment dates, the scope of the market is reduced. Anecdotally, studies of unraveled markets suggest this is because

\footnotetext{
${ }^{17}$ To determine the size we consider for each hospital the average number of fellows for all the years in which the hospital had fellows. The average number of positions per year is 1.79 , the median 1.53 . We first divided our sample in hospitals of size below or above median. The universities of size below median have
} 
when appointments have to be made very early, participants seem to rely more on their personal networks (see e.g. Avery et al. 2001). ${ }^{18}$

There are several possible roles for such networks when appointments are early: they can be sources of otherwise scarce information, they can facilitate transactions when they must be completed quickly, and they can enhance the credibility of commitments made years in advance.

The earlier a market unravels, the less information will be available about candidates, and the more market firms may have to rely on additional, trustworthy sources of information about their prospective applicants. Clearly, GI training directors may be able to receive insider information about internal medicine residents from their own hospital.

In addition, a hospital may be much faster in countering a short fuse offer for a candidate from their own hospital, about whom they have already a lot of information, and who they can interview, if necessary, on short notice, than for a candidate from outside, whom they would first have to arrange a flyout interview.

Finally, superior information about candidates within a network may not only concern the ability of the applicant, but also their preferences about pursuing a GI fellowship in that particular hospital. Indeed Roth and Xing 1997, observed that psychology training directors prefer to make offers to lower ranked candidates if those candidates expressed a credible strong preference for this specific training program. Such information may be more accurate and more easily available for fellows from the

less than $20 \%$ of the fellows. Therefore we also divided our sample in the 100 largest universities that have about $50 \%$ of the fellows, and the smaller ones. 
same hospital. Furthermore, not only information about the reliability of promises that a candidate would accept this offer when made, but also enforcement of this promise may be easier, when the applicant is part of a local network. For example, an internal medicine training director who knows that a fellow accepted a position in the same hospital, may refuse to provide information to other potential employers.

The exact reasons for the demise of the centralized match for gastroenterologists remains an open question. The proximate cause seems to have been the shock to the market from the administrative decision to reduce the number and increase the lengths of GI fellowships required for board certification. Since that time, the number of positions has again stabilized, raising the question of whether this profession would be ready to try using the match again. The results of the present study suggest that reintroducing a centralized match would increase the scope of the market and the mobility of gastroenterologists, as well as allowing matches to be made after more information has become available.

\footnotetext{
${ }^{18}$ In a personal communication, Wing Suen has informed us that he and Hao Li and Ettore Damiano are working on a model of search, in which search costs may be distance related, that may be able to accommodate some of the phenomena reported here.
} 


\section{References}

American Gastroenterology Association, Summary of meeting of the NRMP Board of Directors, 2001, http://www.gastro.org/gi-training/summary-meeting..html.

Avery, Christopher, Andrew Fairbanks and Richard Zeckhauser, "What Worms for the Early Bird? Early Admissions at Selective Colleges", working paper, 2001.

Avery, Christopher, Christine Jolls, Richard A. Posner, and Alvin E. Roth, “The Market for Federal Judicial Law Clerks", University of Chicago Law Review, 68, 3, Summer, 2001, 793-902.

William T. Bauer, William Fackler, Kavita Kongara, Christie Matteoni, Bo Shen and Michael Vaezi, Comment to It's Time to Bring the Best and Brightest Back to Gastroenterology, Gastroenterology vol. 116, No.4, 1999, 1014.

Gale, David and Lloyd Shapley [1962], "College Admissions and the Stability of Marriage," American Mathematical Monthly, 69, 9-15.

Gorelick, Fred S. M.D., "Striking Up the Match", Comment From the Editors Gastroenterology, Vol 117, 1999, 295. 
Haruvy, Ernan, Alvin E. Roth, and M. Utku Ünver, "The Dynamics of Law Clerk Matching: An Experimental and Computational Investigation of Proposals for Reform of the Market," October 2001.

Kagel, John H. and A.E. Roth, "The dynamics of reorganization in matching markets: A laboratory experiment motivated by a natural experiment," Quarterly Journal of Economics, February, 2000, 201-235.

Kamecke, Ulrich, "Wage Formation in a Centralized Matching Market," International Economic Review, 39, 1, February, 1998, 33-53.

Li, Hao and Sherwin Rosen, "Unraveling in Matching Markets," American Economic Review, Vol. 88, 1998, 371-387.

Li, Hao and Wing Suen, "Risk Sharing, Sorting, and Early Contracting", Journal of Political Economy, Vol. 108, 2000, 1058-1091.

Meyer, Gregg S., Itzhak Jacoby, Henry Krakauer, Don W. Powell, Jeanette Aurand and Peggy McCardle "Gastorenterology Workforce Modeling", Journal of the American Medical Association, September 4, 1996, Vol 276, No.9, 689-694.

National Resident Matching Program, Specialties Matching Services, MSMP Data, 1999 Appointments, 1999. 
Rebick, Marcus ["The Importance of Networks in the Market for University Graduates in Japan: A Longitudinal Analysis of Hiring Patterns," Oxford Economic Papers, 2000, 52(3),pp. 471-96]

Roth, A.E. "The Evolution of the Labor Market for Medical Interns and Residents: A Case Study in Game Theory", Journal of Political Economy, Vol. 92, 1984, 991-1016.

Roth, A.E. "New Physicians: A Natural Experiment in Market Organization," Science, 250, 1990, 1524-1528.

Roth, A.E. "A Natural Experiment in the Organization of Entry Level Labor Markets: Regional Markets for New Physicians and Surgeons in the U.K.", American Economic Review, vol. 81, June 1991, 415-440.

Roth, A. E. and Elliott Peranson, "The Redesign of the Matching Market for American Physicians: Some Engineering Aspects of Economic Design," American Economic Review, 89, 4, September, 1999, 748-780.

Roth, Alvin E. and Marilda Sotomayor Two-Sided Matching: A Study in Game-Theoretic Modeling and Analysis, Econometric Society Monograph Series, Cambridge University Press, 1990. 
Roth, A.E. and X. Xing "Jumping the Gun: Imperfections and Institutions Related to the Timing of Market Transactions," American Economic Review, 84, September, 1994, 992-1044.

Roth, A.E. and X. Xing "Turnaround Time and Bottlenecks in Market Clearing: Decentralized Matching in the Market for Clinical Psychologists," Journal of Political Economy, 105, April 1997, 284-329.

Suen, Wing "A competitive theory of equilibrium and disequilibrium in two-sided matching", RAND Journal of Economics, 31, Spring 2000, 101-120. 